\title{
The Effects of an Everyday Life Problem-Solving Centered Preschool Mathematical Program on Children's Mathematical Problem-Solving and Attitude
}

\author{
Sunyoung Yang ${ }^{1}$, Jihyun Kim² \\ Ph. D., Department of Child Development \& Education, Myongji University ${ }^{1}$ \\ Associate Professor, Department of Child Development \& Education, Myongji University ${ }^{2}$ \\ 일상생활 문제해결 중심의 유아수학프로그램이 \\ 유아의 수학적 문제해결력과 수학적 태도에 미치는 효과 \\ 양선영 ${ }^{1}$, 김지현 ${ }^{2}$ \\ 명지대학교 아동학과 박사, 명지대학교 아동학과 부교수 ${ }^{2}$
}

Objectives: This study aimed to examine the effects of an everyday life problem-solving centered preschool mathematical program on young children's mathematical problem-solving and attitude.

Methods: We selected two classes of children aged 5-6 years. There were 23 children in the experiment group and 23 children in the comparison group in S city from June 20, 2018 to August 20,2018 . Using the SPSS WINDOWS 21.0 program, independent samples $t$-tests and corresponding sample $t$-tests were implemented.

Results: The everyday life problem-solving centered preschool mathematical program had positive effects on improving children's mathematical problem-solving but not their mathematical attitude in the experiment group.

Conclusion: By showing the value of preschool mathematical education in everyday life, this study will be helpful improving preschool mathematical programs.

Keywords: mathematical problem-solving, mathematical attitude, everyday life problem-solving, problem-based learning

\section{Introduction}

제4차 산업혁명의 미래사회는 디지털 혁명을 기반으로 사 회 전체가 새로운 패러다임으로 전환될 것으로 예상된다 (Schwab, 2016/2016). 특히, 기존의 교육이 제 4차 산업혁명 기 반의 새로운 패러다임으로 전환되어야 한다는 점에 많은 교 육자들이 동의하고 있다. 다가올 미래사회는 세계가 서로 초 연결되어 시공을 초월한 정보획득이 가능하고, 우리가 전혀 예측하지 못한 문제들을 새롭게 맞이할 가능성이 높다. 또

Corresponding Author: Jihyun Kim, Associate Professor, Department of Child Development \& Education, Myongji University, 34 Geobukgol-ro, Seodaemun-gu, Seoul, Korea

E-mail: jihyunkim@mju.ac.kr
한 인공지능(AI), 사물인터넷, 로봇 등의 활용이 일상화되어 (Schwab, 2016/2016) 일상생활이나 직업생활에서 더 다양한 수학의 활용이 요구될 것이다. 지식 축적을 목표로 했던 기존 교육으로는 미래사회가 필요로 하는 인재를 양성하기 어려 우므로(World Economic Forum [WEF], 2017), 문제해결과 관 련된 정보를 판별하고 활용하여 문제를 해결할 수 있는 능력 과 새로운 정보를 산출해 내는 교육이 교육의 주안점이 될 필 요가 있다. 따라서 수학적 능력 발달의 결정적 시기인 유아기 (Chung et al., 2016)부터 단순히 개념을 습득하고 암기하는 수

(C)The Korean Association of Child Studies

This is an Open Access article distributed under the terms of the Creative Commons Attribution Non-Commercial License (http:// creativecommons.org/licenses/by-nc/4.0) which permits unrestricted noncommercial use, distribution, and reproduction in any medium, provided the original work is properly cited. 
동적인 교육이 아니라 수학적 문제해결력이 신장될 수 있는 수학교육이 이루어져야 한다.

수학은 어떤 문제를 여러 가지 수학적 방법으로 해결하게 함으로써 문제해결의 지혜를 기르고, 한 현상에 담긴 수학적 질서를 이해하도록 하며, 사물의 법칙과 질서에 대한 수학적 이해력을 기르는 학문이다(Ko, 2015). 그러므로 수학 교육은 단지 수학적 지식을 획득하는 것이 아니라 수학적으로 문제 해결하는 능력을 개발하는 것이어야 한다(NCTM, 2000). 수 학적 문제해결력은 주변의 인적, 물리적 환경과 상호작용하면 서 유아가 새로운 지식을 형성하고, 일상의 문제를 해결하기 위해 사전의 수학적 지식을 활용하여 해결책을 찾는 능력이다 (Hong, 2010). 수학적 문제해결력은 유아가 문제를 해결하는 과정에서 수학에 대한 자신의 사전 지식이나 기술을 좀 더 명 확히 이해할 수 있게 만들 뿐만 아니라, 일상생활에서의 다양 한 문제를 합리적이고 창의적으로 해결할 수 있는 능력의 바 탕이 되며(NCTM, 2000), 유아들로 하여금 어떻게 생각하는 가를 배우도록 해 준다. 선행연구(Sperry-Smith, 1997)에 의하 면 다양한 해결책이 내재된 문제를 해결한 경험을 가진 유아 는 융통성 있게 사고하고 여러 의문들을 가지며, 일상생활 속 에서 발생되는 문제들을 해결하며 문제해결의 과정과 기술을 학습했던 유아들은 그렇지 않은 유아들보다 다양한 해결책을 사용하여 문제를 해결할 수 있었다. 유아는 의미 있는 상황에 서 논리적으로 문제를 해결하는 경험을 할 때 수학학습이 용 이하게 이루어지며, 문제해결의 구체적인 경험의 수학적 지식 이 하루 일과 속에서 통합적으로 활용될 때 수학적 문제해결 력이 효과적으로 향상된다(Kwon, 2003). 이는 유아의 수학적 문제해결력은 하루 일과 중 구체적이고 통합적으로 문제를 해 결할 기회가 주어질수록 증진됨을 의미한다. 그러므로 유아의 발달 특성과 유아의 수학적 경험을 연결한 수학적 문제해결력 을 유아기부터 다룰 필요가 있다(J. S. Hwang, 1996).

최근에는 수학학습과 관련한 변인으로 개인의 인지적 요인 뿐만 아니라 정의적 요인인 수학적 태도가 함께 주목받고 있 다(H.-I. Hwang, 2007). 수학적 태도는 유아가 수학에 대해 느 끼는 흥미나 수학과제에 대한 지각, 수학능력에 자아개념, 그 리고 자신의 수학능력에 대한 주위의 기대에 대한 인식을 말 한다(Eccles, 1983). 유아기는 수학에 대해 흥미를 가지고 적극 적으로 문제를 해결하려는 수학적 태도가 형성되는 결정적 시기로, 이 시기에 형성된 태도들은 성장 후에도 쉽게 변화하 지 않는다(H.-I. Hwang, Lee, \& Oh, 2011). 유아는 수학을 실제 맥락 속에서 다양한 전략을 세워 검증하고 또래나 교사와 함 께 의사소통해 나가는 활동을 통해 수학에 대한 자신감과 자
율성, 판단의 자주성을 얻음으로써 긍정적인 수학적 태도를 형성하게 된다(Yackel \& Cobb, 1996). 선행연구(Furinghetti \& Morselli, 2009; Reyes, 1984)에 의하면 수학에 대한 긍정적 태도 는 유아가 지속적으로 수학을 학습하고자 하는 원동력으로 작 용하여 높은 수학성취로 연계되나, 수학에 대한 부정적인 태도 는 수학 학습의 참여도를 낮추게 하여 낮은 수학성취도로 연결 되는 것으로 나타났다. 또한 유아의 수학에 대한 긍정적 태도 는 수학에 대한 거부감 없이 자신감과 흥미를 지니고, 수학적 문제를 해결하기 위해 다른 사람과 협력하는 데에 도움을 주는 것으로 나타났다( $\mathrm{Na} \& \mathrm{Kim}, 2003)$. 따라서 유아에게 의미 있 는 수학활동이 되게 하기 위해서는 수학에 대한 흥미와 동기를 유발시키고 수학에 대한 자신감을 가질 수 있도록 하여 수학에 대한 긍정적인 태도를 형성시키는 것이 중요하다.

수학적 문제해결력을 기르기 위해 시도된 국외의 선행연 구(Beishuizen, Gravemeijer, \& van Lieshout, 1997; Gravemeijer, 1994)를 살펴보면, 수학교육을 일상생활의 문제를 해결하는 방식으로 적용하는 것의 중요성이 강조되고 있다. 유아의 비 형식적 수학지식을 활용하여 일상생활의 문제를 해결해 보도 록 하는 수학활동은 유아의 수학적 이해를 발달시키고, 유아 에게 친숙한 맥락의 수학활동은 유아가 수학적 문제상황을 덜 추상적으로 느끼게 하고 자신의 경험을 문제해결에 더 쉽게 연결시킬 수 있도록 하여 효과적인 전략을 활용하도록 돕는다 는 주장(Huang, 2004; Reder \& Ritter, 1992)이 있다. 즉 제시된 문제의 맥락이 유아에게 친숙한 정도가 문제해결에 영향을 미 친다는 것이다(Rogoff \& Lave, 1984).

국내의 유아의 수학 관련 선행연구들(H.-S. Cho \& Lee, 2012; H. Kim \& Lee, 2018; M. F. Kim \& Kim, 2014; E.-H. Lee \& Kim, 2015; E.-Y. Lee \& Jeon, 2012; Mun \& Cho, 2017; Shin $\&$ Lee, 2003)은 유아를 대상으로 한 다양한 수학활동이 수학 적 문제해결력과 수학적 태도를 증진시키는 데에 효과가 있음 을 밝히고 있다. 그러나 일상적인 유아의 수학적 문제해결 경 험의 관점에서 유아의 수학적 문제해결력에 대한 선행연구를 보았을 때 한계점이 발견되었다. 일부 연구(H.-S. Cho \& Lee, 2012; Mun \& Cho, 2017)를 제외한 대부분의 연구들은 수학 적 어휘가 사용된 그림책을 교사가 선정하여 유아에게 수학개 념을 학습시킨 후 수학적 문제해결력이 향상되었는지를 알아 본 E.-Y. Lee와 Jeon (2012)의 연구와 같이, 교사가 제시한 수학 활동을 유아가 경험해 본 결과로서의 수학적 문제해결력의 향 상을 다루었을 뿐, 유아들이 실제로 문제를 해결해 보는 활동 을 실행한 결과로서의 수학적 문제해결력의 향상을 다루지 못 했다. 그러나 유아의 수학적 문제해결력은 단순히 수학적 지 
식을 활용하여 해결책 알아내기를 목적으로 하는 결과 지향이 아니라 유아로 하여금 어떻게 생각하는가를 배우게 하는 것이 므로(Shin \& Lee, 2003), 실질적으로 수학적 문제를 해결해 본 경험에 의해 더욱 향상될 수 있다(Anderson, 1993).

유아의 수학에 대한 긍정적 태도를 형성하기 위해서는 수 학이 자신의 문제를 해결하는 유용한 도구로 인식되어져야 한 다(NCTM, 2000) 그러기 위해서는 유아들이 실질적으로 자신 들이 처한 문제를 해결하기 위해 수학이 활용되어져야 한다. 그러나 H.-S. Cho와 Lee (2012)의 연구에서와 같이 국내 선행 연구에서는 유아들이 물체를 탐색한 후 교사가 유아들에게 필 요할 것으로 예측되는 물체 관련 의문사항을 제시하면 유아들 이 이를 해결해 보는 활동으로 진행되거나 숲에서 자연물로 할 수 있는 수학 활동(E.-H. Lee \& Kim, 2015)이나 동화책을 읽고 교사가 제시한 활동이 진행된 후 수학적 태도의 변화를 알아보았다(M. F. Kim \& Kim, 2014). 이는 유아가 자신이 처 한 수학적 문제상황을 해결하는 도구로써의 수학의 가치를 인 식하지 못하게 하였다는 한계점을 가진다.

따라서 선행연구의 한계점을 극복하기 위해 이 연구에서는 첫째, 유아들이 실제로 문제를 해결해 보는 활동으로 프로그 램의 효과를 보고자 한다. 수학적 문제해결력은 연령에 따라 발달하나 그 발달 수준이 연령에 의해 결정되는 것이 아니라 누적된 문제해결의 경험에 기인한다(Brown, Bransford, Ferrara, \& Campione, 1983). 실제 경험에서 유아들이 문제해결전략을 배우고 문제해결에 관해 토론하는 것은 매우 유용하며(Charles $\&$ Lester, 1982), 유아들은 성인처럼 논리적으로 사고하지는 않 지만, 시행착오 과정을 통해 나중의 문제해결이나 논리적 사 고의 기초를 세울 수 있다는 주장(Shaw \& Blake, 1998)이 있다. 그러므로 유아들이 실제로 수학적 문제를 해결해 보는 프로그 램이 제공되어야 한다. 둘째, 유아의 일상생활 중의 문제해결 에 중심을 두고자 한다. 유아들은 다양한 일상생활에서 수학 을 경험하며 비형식적 수학지식을 학습한다(Balfanz, Ginsburg, $\&$ Greenes, 2003). 유아에게 친숙하고 다양한 일상생활의 맥락 을 수학학습으로 연결하는 기회 제공은 유아가 수학교육에 관 한 기초 개념을 습득하고 수학적 사고를 형성하도록 하는 데 에 중요하다(Charlesworth, 2000). 유아는 자신의 경험이나 알 고 있는 지식과 관계되고 자신에게 친숙하며 흥미 있는 상황 에서 더욱 효과적으로 학습한다는 주장(Hong, 2004)이 있다. 그러므로 누리과정의 수학적 내용요소를 적용하면서도 유아 의 흥미와 능동적 학습이 일어날 수 있는 일상생활에서의 수 학적 문제를 해결해 보는 경험이 유아에게 제공되어야 한다.

따라서 본 연구에서는 유아의 수학적 문제해결력과 수
학적 태도를 증진시키기 위해 문제중심학습(Problem-Based Learning [PBL])에 기반한 유아수학프로그램을 적용하여 효과 를 검증하고자 한다. 문제중심학습 $(\mathrm{PBL})$ 은 유아가 겪는 실제 적인 상황의 비구조화된 문제를 해결하는 과정을 통해 유아가 필요한 지식을 능동적으로 배울 수 있다는 교육적 접근으로 (Y. Cho, 2001), 학습 과제를 해결해 나가는 데 있어 성인의 지 시나 개입을 최소화하고, 유아 사고 중심의 학습과 토의를 통 해 유아가 개념과 해결책을 스스로 구성해 나가도록 하는 학 습을 말한다(Savery \& Duffy, 1994). 문제중심학습은 학습자의 비판적 사고 성향을 높이고(K. H. Kim, 2001), 자기 주도적 학 습력과 사회성(H. J. Kim, 2001), 문제해결력(K. S. Kim, 2002) 신장에 효과적이며, 학습자의 동기를 유발하여 적극적인 수 업이 가능하도록 한다(H. S. Lee, 2002). 따라서 학습자가 당면 한 실제적 문제를 해결하기 위해 또래 및 성인과 상호협력하 고 주도적 학습을 이끄는 문제중심학습은 유아기 수학교육에 있어서 일상생활의 수학적 문제를 의미 있는 방식으로 해결 할 수 있는 유아의 능력을 키워주기에 적절하다(Huh \& Kang, 2010).

본 연구에서는 일상생활 문제해결 중심의 유아수학프로그 램이 유아의 수학적 문제해결력과 수학적 태도 향상에 효과가 있는지를 검증하고자 한다. 이를 통해 일상생활 문제해결 중 심의 유아수학프로그램의 유용성을 확인하고 일상생활에서의 유아수학교육의 가치를 밝힘으로써, 유아교육·보육 현장에서 실행되고 있는 유아수학프로그램 개선에 기여하고자 한다. 이 상의 문제 제기에 근거하여 설정된 연구문제는 다음과 같다.

\section{연구문제 1}

일상생활 문제해결 중심의 유아수학프로그램은 유아의 수학 적 문제해결력 증진에 유의한 효과가 있는가?

\section{연구문제 2}

일상생활 문제해결 중심의 유아수학프로그램은 유아의 수학 적 태도 증진에 유의한 효과가 있는가?

\section{Methods}

\section{연구대상}

일상생활 문제해결 중심의 유아수학프로그램의 효과를 검증 하기 위해 $S$ 시에 위치한 S어린이집 만 5, 6세 유아 23명은 누 
리과정과 본 연구에서 개발된 프로그램을 적용하는 실험집단 으로, P어린이집 만 5, 6세 유아 23명은 누리과정에 의한 수학 교육만을 운영하는 비교집단으로 임의 표집하였다. 연구대상 으로 표집된 두 어린이집은 일반주택과 아파트가 혼재된 주거 단지에 위치해 있으며, 어린이집에서 수학특별활동이 실시되 지 않고 있었고 유아가 개별 수학사교육을 받은 정도나 가족 의 사회·경제적 수준이 유사하였다. 만 5, 6세 유아는 자신의 비형식적 수학지식을 일상생활의 문제상황에 적용하여 수학 적으로 해결한 경험을 초등학교 입학 이후의 형식적 수학교육 으로 연결할 것으로 기대되는 시기이기 때문에(Hong, 2004) 연구 대상으로 선정하였다. 또한 발달상 만 5세 이후 유아들은 집단으로 놀이하는 경우가 많아 서로의 의견이나 생각의 불 일치로 갈등이 생기고(J. Y. Lee, 1997), 단순 놀이보다는 정보 와 설명을 주고받는 놀이상황에서 수학적 문제상황을 많이 경 험하게 될 것으로 판단되기 때문이다. 검사 실시 전 유아의 부 모에게 연구에 대한 설명문과 동의서를 발송하였으며, 부모의 동의가 이루어진 유아만을 대상으로 연구를 진행하였다.

\section{연구도구}

\section{수학적 문제해결력}

유아의 수학적 문제해결력을 검사하기 위해서 Ward (1993) 의 검사도구를 J. S. Hwang (1996)이 번안하고 이를 C. B. Kim (1998)이 수정 - 보완한 도구를 사용하였다. Ward의 검사도구 는 유사점과 차이점 알아내기 6 문항, 구분짓기 4 문항, 패턴 4 문항, 측정하기 1 문항으로 전체 15 문항으로 구성되어 있다. 이를 C. B. Kim (1998)이 전문가의 내용타당도 검증을 통해 반 복되는 문항을 삭제하고 부재한 문항을 추가한 후 정답률 산 출을 통해 난이도를 조정한 후 최종 분류 5 문항, 패턴 3문항, 수 3 문항, 측정 2 문항, 도형 5 문항, 통계 3 문항의 전체 21 문항 으로 구성하였다.

검사 문항의 점수는 복잡한 규칙 적용과 새로운 방법의 적 용 또는 결과를 말로 설명할 수 있을 경우 다르게 배점하여 세 부 문항에 따라 0-4점까지 받을 수 있으며, 총 점수는 0점에서 부터 49점까지이다. 점수가 높을수록 유아의 수학적 문제해 결력이 높음을 의미한다. 본 척도는 누리과정의 수학적 탐구 하기 5 개 영역을 모두 포함하고 있으며, 유아가 제시하는 해결 안 수준에 따른 배점과 다양한 해결안이 고려될 수 있어 선정 하였다. 측정에 대한 하위척도 문항 예시를 들면, "(판 위에 털 실조각과 종이끈을 압핀으로 고정시킨 두 갈래 길이 있는 그
림을 보여주며) 어떤 길이 더 길까? 어떻게 그 길이 더 긴 줄 알 았니?”가 있다. 각 문항은 유아가 구체물을 직접 다루어 보면 서 진행할 수 있도록 구성되었으며, 검사에 사용된 구체물은 양팔저울, 자동차 그림, 속성 블록, 플라스틱 컵, 사탕, 접시, 클 립, 그래프 그림 등이다. C. B. Kim (1998)의 연구에서 사용된 수학적 문제해결력 전체 점수의 신뢰도(Cronbach's $\alpha$ )는 .75였 고, 이 연구에서도 .75로 양호하게 나타났다.

\section{수학적 태도}

유아의 수학적 태도를 측정하기 위해 Park과 Hwang (2006)이 제작한 ‘수학적 태도 검사' 도구를 사용하였다. 수학적 태도 검 사 도구의 하위 영역은 수학에 대한 흥미, 수학능력에 대한 자 아개념, 과제에 대한 지각, 주위의 격려와 기대로 구성되어 있 다. 총 15 문항으로 유아가 예라고 말하면 1점, 아니오라고 말 하면 0점으로 처리하여, 총점의 범위는 0-15점이다. 점수가 높 을수록 유아가 수학에 대해 긍정적으로 인식하고 있다고 본 다. 유아의 수학적 태도는 흥미, 과제 지각, 수학능력에 대한 자아개념, 주위의 기대에 대한 인식 등이 서로 복잡하게 작용 하며 형성되므로(Eccles, 1983) 이를 측정할 수 있는 본 도구를 선정하였다. 자아개념에 대한 하위척도 문항 예시를 들면, "너 는 다른 친구들보다 수 활동을 더 잘한다고 생각하니?”가 있 다. Park과 Hwang (2006)의 연구에서 사용된 수학적 태도 전체 점수의 신뢰도(Cronbach's $\alpha$ )는 .80이었고 수학적 태도의 하위 변인인 수학에 대한 흥미 .78, 수학능력에 대한 자아개념 .75, 과제에 대한 지각 .74 , 주의의 격려와 기대 .82였다. 이 연구에 서는 하위 변인인 수학에 대한 흥미는 .61, 수학능력에 대한 자 아개념 .78, 자아개념 과제에 대한 지각 .69, 주위의 격려와 기 대는 .68이었으며, 전체 점수의 신뢰도는 .81로 양호하게 나타 났다.

\section{연구절차}

\section{예비검사 및 검사자 훈련}

일상생활 문제해결 중심의 유아수학프로그램이 유아의 수학 적 문제해결력, 수학적 태도에 미치는 효과를 분석하기 위한 측정도구 및 검사방법의 적절성을 알아보기 위해 2018년 5월 8 일부터 5월 11 일까지 4 일에 걸쳐 $\mathrm{S}$ 시에 위치한 $\mathrm{D}$ 어린이집과 $\mathrm{K}$ 어린이집 만 5세아(남아 6명, 여아 6명, 총 12 명)를 대상으로 예비검사를 실시하였다. 검사에 사용될 문항의 이해도와 검사 
에 응답하는 시간 등의 적절성 등을 알아보기 위해 아동학 교 수 1 인에게 의뢰하여 예비검사를 통해 발견된 문제점들을 수 정하였다. 이 때 수정한 부분은 유아가 지나치게 어려워하는 문제에 대해 최대 1 분 이하로 시간을 책정하여 평가할 수 있도 록 하고, 유아가 좀 더 쉽게 이해하고 수용하기 적절한 용어로 수정한 부분이다.

보육교사 1 급 자격증을 소지한 검사자 2 인을 선정하여 총 2 회에 걸쳐 이론적 배경 및 검사방법, 해석방법, 채점방법, 검 사 시 주의사항 등에 관한 사전 훈련을 실시하였다. 연구자가 예비검사 시 녹음한 자료에 대해 각 검사자의 평정 내용을 비 교해 본 결과 .97의 높은 평정자 간 일치도를 보였다.

\section{사전 검사}

예비검사를 통해 수정, 보완을 거쳐 최종적으로 완성된 측정 도구로 실험집단과 비교집단의 유아들에게 사전 검사를 하였 다. 검사는 2018년 6월 5일부터 6월 19일까지 2주일에 걸쳐 실 시되었다. 검사 시 순서효과가 발생되지 않도록 하기 위해 역 균형화 방법(counter-balancing)을 사용하였다. 어린이집의 독 립된 공간에서 훈련을 받은 검사자 2인을 통해 유아 간 1:1 면 접 검사로 진행하였다.

\section{프로그램 실시}

본 연구가 진행되는 동안 3-5세의 연령별 누리과정 프로그램이 실험집단과 비교집단의 어린이집 두 곳에서 모두 동일한 주제 (7월: 여름과 건강/8월: 교통기관)가 실시되었다. 본 연구에서 개발된 프로그램은 2018년 6월 20일부터 2018년 8월 20일까지 9주에 걸쳐 본 연구자가 실험집단에 적용하였다. 오전 자유선 택활동 시간을 활용하여 일주일에 2-3회씩 매회 30분씩 총 18 회기의 프로그램을 실행하였다. 본 프로그램은 대집단으로 모 여 문제를 인식하고 해결안을 제안한 후 소집단으로 모여 제안 된 해결안을 구체화하고 실제로 실행하였다. 전조작기에 해당 하는 유아들이 성인과 같은 방식으로 추론하는 것은 어렵기 때 문에 제안된 해결안을 유아들이 직접 실행하고 평가할 수 있도 록 자유선택활동 시간을 활용하여 유아들이 문제해결과 관련 된 활동을 진행할 수 있도록 하였다. 이와 같이 자유선택활동 시간에 프로그램을 실행한 것은 회기에 맞추어 유아가 대집단 또는 소집단으로 직접 문제해결을 경험 할 수 있도록 시간을 확보하고 문제해결에 참여하지 않는 유아는 기존 어린이집 프 로그램에 맞추어 자유선택활동을 경험하게 하기 위해서이다.
또한 누리과정에 근거하여 교사가 계획한 당일 대소집단활동 시간을 방해하지 않음으로써 실험집단과 비교집단 간에 프로 그램 추가 이외의 다른 변인을 통제하기 위해서였다. 실험집단 에서 본 프로그램이 진행되는 동안 비교집단은 누리과정 주제 에 근거하여 자유선택놀이를 진행하였다. 본 실험을 진행한 연 구자는 보육현장 9년 이상의 경력을 가졌으며 원장 자격을 소 지하고 박사과정을 수료한 아동학 전공자였다.

일상생활 문제해결 중심의 유아수학프로그램 본 연구에서 실시된 유아수학프로그램은 Barrows (1988/2005)의 문제중심 학습의 6단계에 기초하였다. 6 단계 중 문제해결을 위한 '자료 수집 단계'를 유아가 비형식적 지식을 적용하는 '해결안 제안 하기'로, '학습결과 정리 및 평가단계'를 유아들이 해결안을 직 접 실행하여 경험한 후 가장 적합한 ‘해결안 선택하기’로 수정. 보완하여 유아의 발달에 적합한 7단계로 적용하였다. 일반적 인 문제중심학습은 제시된 문제 해결을 위해 개별학습을 통 한 소집단별 논의를 통해 해결안을 제안하고 전체 평가를 통 해 제안된 해결안 중 최적의 것을 선택하는 것이다. 그러나 유 아 수학교육의 목표는 유아가 일상생활로부터 획득한 비형식 적 지식을 활용하여 자신의 문제를 해결하는 기초 능력을 기 르는 것이므로 성인의 문제해결을 위한 자료수집 과정과 유아 가 자신의 비형식적 지식을 문제해결에 연결하는 과정은 동 일 선상에 있다고 볼 수 있다. 또한 전조작기의 유아들은 성인 과 같은 방식의 추론이 어렵기 때문에 유아들이 제안한 해결 안들을 평가하기 위해서는 각각의 실행안을 실제적으로 실시 해 본 후 평가할 수 있어야 한다. 본 연구에서는 기존의 선행연 구들에서 교사가 유아에게 흥미 있을 것으로 예측한 수학활동 을 제공하여 수학교육이 실시되었던 것과 달리 유아들이 어린 이집 일상생활을 하면서 자주 경험하는 문제들을 자신들의 비 형식적 수학지식을 활용하여 해결하는 방식으로 수학교육을 실시하였다. 이를 위해 현장 교사들의 요구도 분석결과(Yang, 2019)와 H.-S. Cho와 Shin (2016)의 연구를 참조하여 문제상황 을 설정하였다. 예를 들면, 블록영역에서 놀고 싶은데 매번 빨 리 차지하는 친구들로 인해서 놀이할 수 없을 때 벌어지는 문 제상황이다. 유아들이 경험하는 일상생활 중의 세 가지 가설 적 문제상황(블록놀이, 역할놀이, 실외놀이)의 편지글을 매개 로 하여 각 에피소드 당 6회기씩 총 18 회기로 구성되었다. 1 회기에는 편지글에서 제시하고 있는 문제상황을 인식하고 적 절한 해결안을 제안하며, 2 회기에는 자신들이 제안한 해결안 을 소그룹으로 모여 구체화하고 이를 대그룹으로 발표한다. $3,4,5$ 회기에는 소집단별로 해결안을 실행하고, 6 회기에는 소 
그룹별로 실행해 본 해결안들에 대해 평가하고 최종안을 선택 하는 것으로 구성된다. 이를 블록놀이로 예를 들면, 블록영역 에서 반 아이 모두 놀이할 수 있는 해결책을 찾기 위해 유아들 은 대집단으로 모여 주어진 편지글에서 제시된 문제가 무엇 인지를 인식하고, '빨리 놀고 자리 바꿔주기', ‘블록 영역 넓히 기', ‘오늘하고 내일로 나눠 놀이하기' 등의 비형식적 수학지식 을 활용하여 유아 스스로 문제해결안을 제안한다. 이후 유아 들은 소집단으로 모여 제시된 해결안을 구체적으로 실행할 수 있는 실행방법을 사전 지식과 경험을 활용하여 계획한다. 계 획된 실행안을 다른 또래에게 설명하는 시간을 통해 다른 유 아와 사고를 공유하고, 각 계획안을 소집단별로 실행한 후 분 석하고 평가하여 최종적인 해결안을 선택하며 마무리한다. 각 활동은 3-5세 연령별 누리과정의 수학적 탐구하기의 내용요 소인 수와 연산, 공간과 도형, 측정, 규칙성, 자료수집과 결과 나타내기를 교육내용으로, 대소집단의 형태로 진행되도록 구 성되었다. 전체 18 회기의 구성은 블록놀이, 역할놀이, 실외놀 이의 3 가지 에피소드별 6회기 단위가 반복되며, 이 중 블록놀 이 회기구성은 Appendix 1과 같다.

\section{사후 검사}

사후 검사는 2018년 8월 21일부터 8월 31일 사이에 사전검사 와 동일한 방법과 내용으로 실시되었다.

\section{자료분석}

일상생활 문제해결 중심의 유아수학프로그램이 유아의 수학 적 문제해결력, 수학적 태도에 미치는 효과를 알아보기 위해 SPSS WINDOWS 21.0 (IBM Co., Armonk, NY) 프로그램을 사 용하여 다음과 같이 분석하였다. 연구대상자의 인구통계학적 분포를 파악하기 위해 교차분석을 실시하여 빈도와 백분율을 산출하였고, 연구도구의 신뢰도 검증을 위해 Cronbach's $\alpha$ 를 산출하였다. 또한 일상생활 문제해결 중심의 유아수학프로그 램을 실시한 실험집단과 실시하지 않은 비교집단의 사전 동질 성을 확인하고 프로그램 실시의 효과검증을 위해 독립표본 $t$ 검증을 실시하였다. 이어서 각 집단 내의 사전검사 점수와 사 후검사 점수 간의 차이를 알아보기 위한 대응표본 $t$ 검증을 추 가적으로 실시하였다.

\section{Results}

\section{일상생활 문제해결 중심의 유아수학프로그램이 유아의 수학적 문제해결력에 미치는 효과}

일상생활 문제해결 중심의 유아수학프로그램이 유아의 수학 적 문제해결력에 미치는 효과를 검증하기 위하여 프로그램 처 치 전, 집단 간 동질성을 독립표본 $t$ 검증을 통해 확인하였다. Table 1에서 보는 바와 같이 유아수학프로그램을 실시하기 전 유아의 수학적 문제해결력에 있어서 실험집단 $(M=25.65, S D$ $=7.85)$ 과 비교집단 $(M=28.22, S D=7.93)$ 은 통계적으로 유의 한 차이가 나타나지 않았다. 이로써 실험집단과 비교집단 간 사전 동질성은 확보되었다.

프로그램 투입 후 실험집단과 비교집단의 수학적 문제해결 력 점수의 차이를 비교한 결과 유아의 수학적 문제해결력은 실험집단 $(M=40.35, S D=7.54)$ 이 비교집단 $(M=34.00, S D=$ 8.93)보다 높았으며, 통계적으로 유의한 차이가 나타났다 $(t=$ $2.61, p<.05)$. 이러한 결과는 일상생활 문제해결 중심의 유아 수학프로그램이 유아의 수학적 문제해결력 증진에 효과가 있 음을 말해준다.

추가로 실험집단에서 프로그램 투입 후 사전점수와 비교 했을 때 사후점수에서 실제적인 향상의 여부를 확인하기 위 해 실험집단과 비교집단의 검사 시기에 따른 대응표본 $t$ 검증 을 실시하였다. Table 2에서 보는 바와 같이 실험집단의 유아 는 프로그램 처치 전 수학적 문제해결력 $(M=25.65, S D=7.85)$ 에 비해 처치 후의 수학적 문제해결력 $(M=40.35, S D=7.54)$ 에 유의한 향상을 보였다 $(t=-10.38, p<.001)$. 비교집단의 유아들 도 프로그램 처치 전 수학적 문제해결력 $(M=28.22, S D=7.93)$ 에 비해 처치 후의 수학적 문제해결력 $(M=34.00, S D=8.93)$ 에 유의한 향상을 보였으나 $(t=-2.82, p<.05)$, Figure 1 과 같이 그 향상의 폭이 실험집단에 미치지 못하였다. 따라서 일상생활 문제해결 중심의 유아수학프로그램을 경험한 실험집단에서 비교집단에 비해 크게 수학적 문제해결력 점수의 향상이 나타 났음을 확인할 수 있었다. 이러한 결과를 그림으로 나타내면 Figure 1 과 같다.

\section{일상생활 문제해결 중심의 유아수학프로그램이 유아의 수학적 태도에 미치는 효과}

일상생활 문제해결 중심의 유아수학프로그램이 유아의 수학 적 태도에 미치는 효과를 검증하기 위하여 프로그램 처치 전, 
Table 1

Differences in Pre and Post Mathematical Problem-Solving Scores Between Groups

\begin{tabular}{lcccccc}
\hline $\begin{array}{l}\text { Mathematical problem } \\
\text { solving }\end{array}$ & \multicolumn{2}{c}{ Pre } & & \multicolumn{3}{c}{ Post } \\
& Experimental group & Comparative group & & Experimental group & Comparative group \\
& $M(S D)$ & $M(S D)$ & $t$ & $M(S D)$ & $M(S D)$ & $t$ \\
\cline { 2 - 7 } & $25.65(7.85)$ & $28.22(7.93)$ & -1.10 & $40.35(7.54)$ & $34.00(8.93)$ & $2.61^{*}$ \\
\hline
\end{tabular}

Note. $N=23$.

${ }^{*} p<.05$.

Table 2

Differences in Pre and Post Mathematical Problem-Solving Scores in Groups

\begin{tabular}{lcccccc}
\hline Mathematical problem & \multicolumn{2}{c}{ Experimental group } & & \multicolumn{2}{c}{ Comparative group } \\
solving & Pre & Post & & & Pre & Post \\
& $M(S D)$ & $M(S D)$ & $t$ & $M(S D)$ & $M(S D)$ & $t$ \\
\cline { 2 - 6 } & $25.65(7.85)$ & $40.35(7.54)$ & $-10.38^{* * *}$ & $28.22(7.93)$ & $34.00(8.93)$ & $-2.82^{*}$ \\
\hline
\end{tabular}

Note. $N=23$.

${ }^{*} p<.05 .{ }^{* * *} p<.001$.

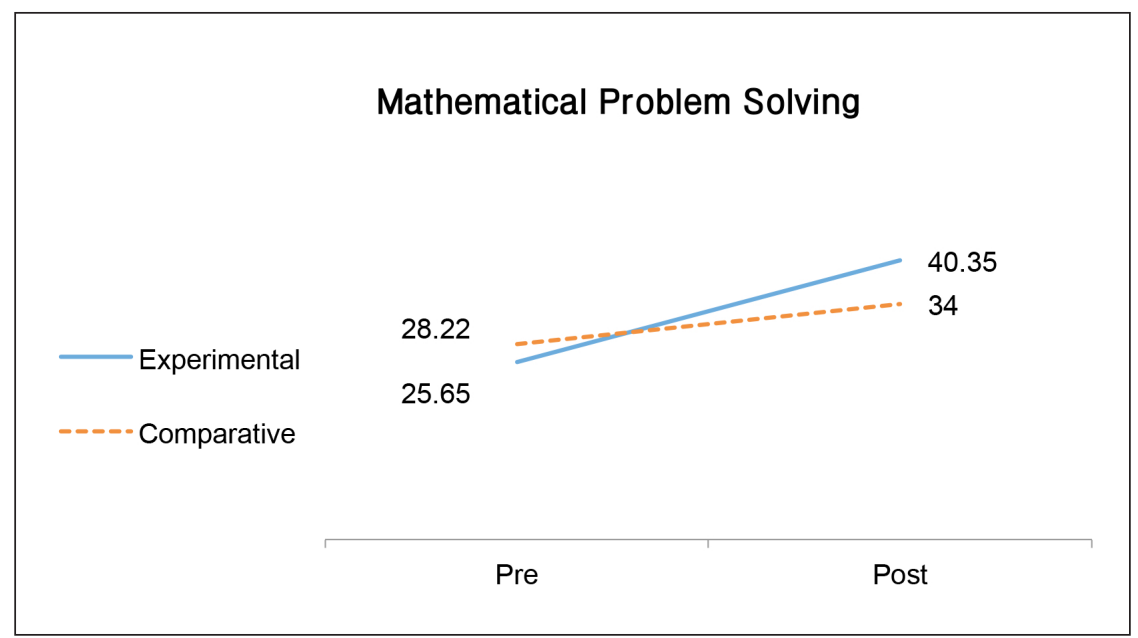

Figure 1. Comparison of pre and post mathematical problem-solving scores between groups.

집단 간 동질성을 독립표본 $t$ 검증을 통해 확인하였다. Table 3 에서 보는 바와 같이 유아수학프로그램을 실시하기 전 유아 의 수학적 태도의 사전검사 총점에서 실험집단 $(M=10.83, S D$ $=3.24)$ 과 비교집단 $(M=11.96, S D=2.83)$ 간에 유의한 차이가 없었다. 하위 점수를 살펴보았을 때에는 '주위의 격려와 기대' 항목의 점수가 실험집단 $(M=2.91, S D=.85)$ 보다 비교집단 $(M$ $=3.43, S D=.90)$ 에서 유의하게 더 높게 나타났고, 그 외 항목 에서는 유의한 차이가 없었다. 이를 바탕으로 전체적으로 수 학적 태도의 사전 동질성이 확보되었다고 볼 수 있다. 그러나 사후검사에서 실험집단 $(M=11.48, S D=2.09)$ 과 비교집단 $(M$ $=11.22, S D=2.13)$ 은 통계적으로 유의한 차이가 나타나지 않
았다. 이는 일상생활 문제해결 중심의 유아수학프로그램이 유 아의 수학적 태도 증진에 이 시기 동안 효과를 가져오지 못했 음을 말해준다.

추가로 실험집단에서 프로그램 투입 후 사전점수와 비교 했을 때 사후점수에서 실제적인 향상의 여부를 확인하기 위 해 실험집단과 비교집단의 검사 시기에 따른 대응표본 $t$ 검증 을 실시하였다. Table 4에서 보는 바와 같이 실험집단의 유아 는 실험 전 수학적 태도 $(M=10.83, S D=3.24)$ 에 비해 실험 후 수학적 태도 $(M=11.48, S D=2.09)$ 가 향상되었으나 통계적으 로 유의하지 않았다. 이에 비해 비교집단의 유아는 실험 전 수 학적 태도 $(M=11.96, S D=2.83)$ 에 비해 실험 후 수학적 태도 
Table 3

Differences in Pre and Post Mathematical Attitude Scores Between Groups

\begin{tabular}{|c|c|c|c|c|c|c|}
\hline \multirow{2}{*}{ Mathematical attitude } & \multicolumn{2}{|c|}{ Pre } & \multicolumn{3}{|c|}{ Post } & \multirow{2}{*}{$t$} \\
\hline & $\begin{array}{l}\text { Experimental } \\
\text { group }\end{array}$ & $\begin{array}{l}\text { Comparative } \\
\text { group }\end{array}$ & $t$ & $\begin{array}{l}\text { Experimental } \\
\text { group }\end{array}$ & $\begin{array}{c}\text { Comparative } \\
\text { group }\end{array}$ & \\
\hline Total score & $10.83(3.24)$ & $11.96(2.83)$ & -1.22 & $11.48(2.09)$ & $11.22(2.13)$ & -.85 \\
\hline Interest in mathematics & $1.48(.79)$ & $1.48(.67)$ & .00 & $1.52(.59)$ & $1.17(.58)$ & -.23 \\
\hline Perception of a task & $1.87(1.06)$ & $2.35(.65)$ & -1.85 & $2.13(1.01)$ & $2.17(.89)$ & -.16 \\
\hline Encouragement and expectation by the surrounding & $2.91(.85)$ & $3.43(.90)$ & $-2.03^{*}$ & $3.00(.95)$ & $3.52(.79)$ & $-2.02 *$ \\
\hline
\end{tabular}

Note. $N=23$.

${ }^{*} p<.05$.

Table 4

Differences in Pre and Post Mathematical Attitude in Groups

\begin{tabular}{|c|c|c|c|c|c|c|}
\hline \multirow[b]{3}{*}{ Mathematical attitude } & \multicolumn{2}{|c|}{ Experimental group } & \multirow[b]{3}{*}{$t$} & \multicolumn{2}{|c|}{ Comparative group } & \multirow[b]{3}{*}{$t$} \\
\hline & Pre & Post & & Pre & Post & \\
\hline & $M(S D)$ & $M(S D)$ & & $M(S D)$ & $M(S D)$ & \\
\hline Interest in mathematics & $1.48(.79)$ & $1.52(.59)$ & -.23 & $1.48(.67)$ & $1.17(.58)$ & -2.08 \\
\hline Self-conceptions of mathematical ability & $4.57(1.47)$ & $4.83(1.19)$ & -.81 & $4.65(1.53)$ & $4.34(1.15)$ & -1.05 \\
\hline
\end{tabular}

Note. $N=23$.

$(M=11.22, S D=2.13)$ 가 낮아졌으나 통계적으로 유의하지 않 았다.

\section{Discussion}

이 연구는 만 5, 6세 유아를 대상으로 일상생활 문제해결 중심 의 유아수학프로그램을 적용한 후 유아의 수학적 문제해결력 과 수학적 태도 증진에 대한 효과를 검증하는 데 목적이 있다. 일상생활 문제해결 중심의 유아수학프로그램을 적용한 효과 를 논의해 보면 다음과 같다.

첫째, 일상생활 문제해결 중심의 유아수학프로그램이 유아 의 수학적 문제해결력을 증진시키는 데 효과가 있었다. 이는 일상생활 속에서 일어나는 다양한 수학적 문제를 유아가 자 신의 사전 지식과 경험을 활용하여 여러 가지 방법으로 해결 해 보는 것은 유아의 수학적 문제해결력을 증진시킬 수 있다 는 것을 의미한다. 이러한 결과는 유아의 수학적 문제해결과
유아의 사전 경험이 서로 관련될 때 유아의 수학적 문제해결 력이 더 향상되었다는 연구결과(Shin \& Lee, 2003)와 일치한 다. 또한 일상생활 속에서 문제를 해결해 보는 과정과 기술을 학습했던 유아들이 그러한 경험을 갖지 못했던 유아들보다 문 제를 해결하는 데에 있어서 더 다양한 해결책을 제안하였다는 연구결과(Sperry-Smith, 1997)와 같은 맥락이다. 어린이집이나 유치원의 일상생활 중 유아들 간의 문제나 갈등이 발생하면 유아들끼리 해결하기보다 대부분의 경우 교사가 일방적으로 개입하여 갈등을 해결하여(H. J. Kim \& Lee, 2001), 유아들이 문제를 해결하는 과정을 교육적으로 접근할 기회를 놓치게 된 다. 그러나 본 연구에서 적용된 일상생활 문제해결 중심의 유 아수학프로그램에서는 일상생활의 문제를 교사의 개입에 의 해 해결하기보다 유아들이 자신들의 비형식적 지식과 경험을 활용하여 주도적으로 문제를 해결해 보는 수학교육의 기회로 활용하였다. 수학적 문제해결력은 단순히 학습지 내에 존재하 는 수학문제를 풀이하는 것에 국한하는 것이 아니라, 일상생 활에서 유아들이 대면하는 문제상황을 수학적으로 해결해 나 
간다는 차원에서 유용한 일상생활 능력이다. 이 연구에서 유 아의 일상생활 문제를 수학적으로 해결할 수 있는 경험을 제 공하였다는 점은 수학적 문제해결력의 일상적 활용도에 대해 시사하는 바가 크다.

또한 일상생활 문제해결 중심의 유아수학프로그램이 유 아의 수학적 문제해결력 증진을 가져온 것은 문제중심학습 $(\mathrm{PBL})$ 의 교수학습방법을 기반하여 프로그램이 구성되었기 때 문이다. 수학적 문제해결력 증진에 관여하는 제 요인 중 가장 중요한 발달요인은 문제해결 절차를 통제하는 상위인지능력 으로, 수학적 문제해결력 증진을 위해서는 상위인지능력을 향 상시키는 것이 중요하다(Brown et al., 1983). 상위인지능력은 문제를 인식하고 해결 전략을 계획하며 문제해결에 유용한 지 식을 탐색하는 능력이다. 또한 자신의 한계를 인식하고, 자신 이 선택한 전략의 효율성을 검토하고 성공과 실패를 평가하 는 능력이다(Brown et al., 1983). 본 연구의 유아수학프로그램 에서 기반을 둔 문제중심학습(PBL)은 문제상황을 인식하고 해결안 제안하기, 제시된 해결안 구체화하기, 구체화된 해결 안 발표하기, 소집단별로 해결안 실행하기, 실행한 해결안 평 가하고 최종안 선택하기의 단계를 거쳐 문제를 해결하도록 구 성되었다. 이처럼 문제중심학습의 일련의 과정은 상위인지능 력의 내용과 일맥상통한다. 그러므로 수학적 문제해결력 증진 을 위하여 문제중심학습 $(\mathrm{PBL})$ 방법을 적용한 것은 유아의 상 위인지능력의 발달을 지원할 수 있었음을 알 수 있다. 이 연구 에서 문제를 해결하기 위해 대소집단으로 모여 또래나 교사 와 토론하고 실행하는 과정은 유아의 수학적 문제해결력 증진 을 촉진하였을 것으로 예측된다. 이는 Vygotsky의 내면화 과정 으로 유아가 자신보다 유능한 또래나 성인의 도움으로 발달 이 이루어지는 기제와 같은 맥락이다. 이러한 결과는 서로의 생각을 공유하고 서로 절충하고 합의해 보는 경험은 문제해 결에 효과적이라는 Oh와 $\mathrm{Kim}$ (1997)의 연구와도 같은 맥락이 다. 이로써 유아의 가설적 일상생활 문제상황을 문제중심학습 $(\mathrm{PBL})$ 의 교수학습방법으로 접근하는 것이 수학적 문제해결력 을 증진하기에 적절하였음을 알 수 있다.

둘째, 일상생활 문제해결 중심의 유아수학프로그램이 유아 의 수학적 태도의 사전, 사후검사 점수의 통계적 변화에서 긍 정적 효과를 미치지 못 하였다. 이 결과는 일상적 경험에 기초 한 수학교육이 유아의 수학에 대한 긍정적 태도에 효과가 있 다는 연구결과(Jung \& Choi, 2006; K. S. Kim, 2009; Seo, 2008) 와 상반된 결과이다. 수학적 태도에 대한 정의는 연구자의 관 점에 따라 다르게 정의되고 그 의미와 강조점이 달라지는 복 합적인 요인들에 의해 구성된다(K. S. Kim, 2009). 수학적 태
도는 과거의 학습경험에서 형성되는데 수학에 대한 반복된 감 정, 반복된 감정반응의 자동화로부터 형성되거나 이미 존재하 는 태도가 유사성을 가진 새로운 과제에 그대로 이입되어 형 성된다. 이는 수학적 태도 등의 정의적 변인은 일정 시간이 지 나야 효과가 나타날 수 있는 변인일 가능성을 나타내므로 유 아들이 수학활동에 대한 경험이 지속해서 쌓여감으로써 효과 가 측정될 수 있을 것이다. 따라서 추수효과를 검증해 볼 필요 성이 있으며, 일상생활 중심의 유아수학프로그램이 유아의 수 학적 태도에 미치는 효과에 대해서는 앞으로 면밀한 연구가 진행되어야 할 것으로 사료된다. 또한 이러한 상반된 결과는 선행연구와 본 연구에서 사용된 '수학적 태도'의 검사 도구가 서로 상이하여 나타난 것으로 유추해 볼 수 있다. 선행연구에 서 사용한 수학적 태도의 하위 변인은 흥미, 유능감, 끈기(K. S. Kim, 2009; Seo, 2008)이거나 자신감, 학습에 대한 열의, 선호 도, 유능감, 타인평가인식(Jung \& Choi, 2006)이었다. 반면 본 연구에서 사용된 수학적 태도의 하위 변인은 흥미, 자아개념, 과제지각, 주위의 격려와 기대로 선행연구와 상이하였다. 다 양한 정의적 특성 중 유아의 수학에 가장 큰 영향을 미치는 변 인의 하나로 자아개념을 들 수 있다(J. Lee, 2015). 수학적 자아 개념은 수학교과와 관련지어 자신을 어떻게 지각하고 있는가 를 평가하는 것이다(Ha \& Kim, 2017). 긍정적인 수학적 자아 개념은 학습자의 수학 학습동기를 강화하고, 적극적인 수학문 제 해결자가 되도록 돕는다(Ha \& Kim, 2017). 선행연구에서 수학적 태도 하위 변인으로 흥미, 유능감, 끈기 등을 측정한 연 구(K. S. Kim, 2009; Seo, 2008)에서는 총 6문항에서 4문항이 흥 미영역을 측정하여 유아의 수학에 대한 흥미의 변화에 주안점 을 두었다. 또한 선호도, 자신감, 학습에 대한 열의, 유능감, 타 인평가인식 등을 측정한 연구(Jung \& Choi, 2006)에서는 전체 수학적 태도에 긍정적 효과가 있었으나 이 중 수학적 자아개 념과 연결된 '자신감' 하위변인에서는 효과가 없는 것으로 나 타났다. 반면, 본 연구에서는 총 15 문항 중 ‘흥미'에 대한 문항 은 2문항이었고 '자아개념'에 대한 문항은 6 문항으로 하위 변 인 중 가장 많은 문항으로 구성되었다. 이러한 이유에서 선행 연구와 본 연구의 수학적 태도의 결과가 상이한 것으로 유추 해 볼 수 있다. 이러한 결과는 유아의 수학 활동을 계획할 때 단순히 수학이 재미있다는 흥미만을 고려할 것이 아니라 유아 자신이 수학을 잘한다거나 잘할 수 있다는 자아개념을 변화시 킬 수 있는 방법을 함께 고려해야 함을 시사한다.

이 연구가 가지는 의의는 유아들이 일상생활 중의 문제를 해결한 결과로서의 수학적 문제해결력 증진의 효과를 알아보 았다는 점이다. 유아의 수학적 문제해결력은 단순히 수학 지 
식의 획득에만 의해서라기보다 유아가 문제를 해결하기 위해 서 어떻게 생각해야 하는가를 배울 수 있는 실제적인 수학문 제의 해결을 통해 더욱 향상된다(Anderson, 1993; Shin \& Lee, 2003). 그러나 국내의 유아의 수학적 문제해결력 관련 선행 연구들(H.-S. Cho \& Lee, 2012; E. Y. Lee \& Jeon, 2012; Mun \& Cho, 2017)은 교사의 계획 및 주도를 통한 수학 지식의 획득정 도의 증진이나 타 교과와의 통합 관련만을 밝혀왔다. 유아는 자신의 사전 경험이나 지식과 관계되고 자신에게 친숙한 상황 에서 더욱 효과적으로 학습한다(Hong, 2004). 그러므로 유아 의 수학적 문제해결력을 유아의 일상적 맥락과 분리되지 않고 유아가 빈번히 대면하는 일상생활의 문제들을 실제로 해결해 보는 경험을 통해 그 효과를 알아보았다는 측면에서 의의가 있다.

이 연구가 가지는 한계점에 기초하여 후속 연구를 제언하 고자 한다. 첫째, 이 연구는 구성주의에 기반한 문제중심학습 을 교수학습방법으로 채택하고, 수학적 문제해결력과 함께 수 학적 태도의 증진을 알아보는 연구이다. 따라서 프로그램 실 시 전 담임교사의 보고를 통해 일반적인 유아의 범주에서 벗 어난 유아를 연구대상에서 제외하였다. 후속 연구에서는 유아 의 지능을 직접 검사하여 의도되지 않은 변인의 영향을 조절 한 후 연구가 진행될 필요가 있겠다. 둘째, 이 연구는 일상생활 문제해결 중심의 유아수학프로그램이 유아의 수학적 문제해 결력 증진에 효과가 있음을 확인하였다. 추후 연구에서 유아 를 대상으로 교사 주도의 형식적 수학교육 프로그램이 이루어 지는 집단과의 비교를 통해 본 연구의 프로그램의 또 다른 측 면의 가치를 검증할 필요가 있겠다. 셋째, 이 연구에서 개발된 유아수학프로그램은 유아의 수학적 태도에 긍정적 효과를 미 치지 못하는 것으로 나타났다. 후속 연구에서는 문제 상황을 교실에서 실제로 일어나고 있는 상황과 연결하거나 유아의 변 화를 인식할 수 있는 담임교사를 통해 수학적 태도의 효과를 검증할 필요가 있겠다. 마지막으로 본 연구에서는 유아들의 자유선택활동 시간을 활용하여 프로그램을 진행하였다. 향후 보육현장에서 본 프로그램을 실시할 경우 현장의 상황에 맞게 자유선택활동 시간이나 대소집단 활동 시간에 융통적으로 적 용할 수 있겠다.

\section{Notes}

This article is a part of the first author's doctoral dissertation.

\section{Conflict of Interest}

No potential conflict of interest relevant to this article was reported.

\section{References}

\section{In English}

Anderson, J. R. (1993). Problem solving and learning. American Psychologist, 48(1), 35-44. doi:10.1037/0003-066x.48.1.35

Balfanz, R., Ginsburg, H. P., \& Greenes, C. (2003). The big math for little kids early childhood mathematics program (Early childhood corner). Teaching Children Mathematics, 9(5), 264-268.

Beishuizen, M., Gravemeijer, K. P. E., \& van Lieshout, E. C. D. M. (1997). The role of contexts and models in the development of mathematical strategies and procedures. Utrecht, NL: Freudenthal Institute.

Brown, A. L., Bransford, J. D., Ferrara, R. A., \& Campione, J. C. (1983). Learning to remember and understanding. In P. H. Mussen (Series Ed.) \& J. H. Flavell \& E. M. Markman (Vol. Eds.), Handbook of child psychology: Cognitive development (4th ed., Vol. 3, pp. 77-166). New York: John Wiley \& Sons.

Charles, R., \& Lester, F. (1982). Teaching problem solving what, why \& how. Palo Alto, CA: Dale Seymour Publications.

Charlesworth, R. (2000). Experiences in math for young children (4th ed.). Boston, MA: Wadsworth, Cengage Learning.

Eccles, J. (1983). Expectancies, values, and academic behaviors. In J. T. Spence (Ed.), Achievement and achievement motives: Psychological and sociological approaches (pp. 75-146). San Francisco, CA: W. H. Freeman and Company.

Furinghetti, F., \& Morselli, F. (2009). Every unsuccessful problem solver is unsuccessful in his or her own way: Affective and cognitive factors in proving. Educational Studies in Mathematics, 70(1), 71-90. doi:10.1007/s10649-008-9134-4

Gravemeijer, K. P. E. (1994). Developing realistic mathematics education. Utrecht, NL: Freudenthal Institute.

Huang, H.-M. E. (2004). The impact of context on children's performance in solving everyday mathematical problems 
with real-world settings. Journal of Research in Childhood Education, 18(4), 278-292. doi:10.1080/02568540409595041

NCTM. (2000). Principles and standards for school mathematics. Reston, VA: Author.

Reder, L. M., \& Ritter, F. E. (1992). What determines initial feeling of knowing? Familiarity with question terms, not with the answer. Journal of Experimental Psychology: Learning, Memory, and Cognition, 18(3), 435-451. doi:10.1037/02787393.18.3.435

Reyes, L. H. (1984). Affective variables and mathematics education. The Elementary School Journal, 84(5), 558-581.

Rogoff, B., \& Lave, J. (1984). Everyday cognition: Its development in social context. Cambridge, MA: Harvard University Press.

Savery, J. R., \& Duffy, T. M. (1994). Problem-based learning: An instructional model and its constructivist framework. Educational Technology, 35(5), 31-38.

Shaw, J. M., \& Blake, S. S. (1998). Mathematics for young children. Upper Saddle River, NJ: Prentice Hall.

Sperry-Smith, S. (1997). Early Childhood mathematics. Boston, MA: Allyn \& Bacon.

World Economic Forum. (2017). 2017 global risks report (12th ed.). Geneva, CH: World Economic Forum.

Yackel, E., \& Cobb, P. (1996). Sociomathematical norms, argumentation, and autonomy in mathematics. Journal for Research in Mathematics Education, 27(4), 458-477. doi:10.2307/749877

\section{In Korean}

Barrows, H. S. (2005). The tutorial process (3th ed., J.-D. Seo, B.-H. Ahn, \& H. J. Son, Trans.). Seoul: Sungkyunkwan University Press. (Original work published 1988)

Cho, H.-S., \& Lee, M.-O. (2012). The effects of the mathematiccenter activity based upon inquiry on the children's mathematical problem-solving ability and attitude toward mathematics. Korean Education Inquiry, 30(1), 25-44.

Cho, H.-S., \& Shin, N.-J. (2016). The difference on children's age characteristics of young children's peer conflicts demanded teacher-mediated instruction. Early Childhood Education Research \& Review, 20(6), 121-140.

Cho, Y. (2001). An examination of Problem-Based Learning $(\mathrm{PBL})$ as a teaching-learning model for infusing creative, critical thinking with knowledge of subjects. The Journal of Elementary Education, 14(3), 295-316.

Chung, C., Back, K., Choi, H., Jung, M., Hong, H., \& Jeong, H. (2016). Yuasuhakgyoyuk [유아수학교육]. Paju, KR: Yangseongwon.

Ha, J. S., \& Kim, J. K. (2017). Analysis of the structural relationship of mathematics self-conception, mathematics academic motivation, cognitive load and mathematics academic achievement. Journal of Learner-Centered Curriculum and Instruction, 17(13), 1-20. doi:10.22251/jlcci.2017.17.13.1

Hong, H. (2004). The development of a coherent mathematics curriculum for pre-k through grade 2. Journal of Early Childhood Education, 24(2), 289-310.

Hong, H. (2010). The future directions and challenges in early childhood mathematics education. Early Childhood Education Research \& Review, 14(4), 29-51.

Huh, N., \& Kang, O. K. (2010). A study to develop criteria to judge mathematical problems and a learning model in mathematics problem-based learning. Journal of Educational Research in Mathematics, 20(3), 255-274.

Hwang, H.-I. (2007). A study on the relationship of personal variables to mathematical learning potential in young children. Early Childhood Education Research \& Review, 11(4), 343-362.

Hwang, H.-I., Lee, H.-E., \& Oh, K.-N. (2011). A study on the differences of young child's problem-solving based on the level of mathematics attitudes and abilities in the process of dynamic assessment. The Journal of Korea Open Association for Early Childhood Education, 16(2), 141-158.

Hwang, J. S. (1996). An effective approach to mathematical education for young children: A comparative study of childactivity-centered methods using concrete materials and teachercentered methods using worksheets (Doctoral dissertation). Retrieved from http://www.riss.kr/link?id=T7456398

Jung, J.-S., \& Choi, M.-S. (2006). A study on the effects of mathematical activities on the mathematical concept and attitude of young children. The Journal of Child Education, 15(4), 231-242.

Kim, C.-B. (1998). The effects on children's mathematical ability of the activity-centered learning method based upon the parent-teacher's partnership involvement program (Doctoral dissertation). Retrieved from http://www.riss.kr/ link?id=T10399464

Kim, H., \& Lee, J. (2001). Characteristics of young children's peer conflicts according to the ages and the sex compositions of conflicting children. The Journal of Educational Research, 39(2), 99-119.

Kim, H., \& Lee, S. (2018). The influence of mathematical process activity utilizing block play on mathematical ability and attitude of young children. The Journal of Korea Open Association for Early Childhood Education, 23(4), 205-229. doi:10.20437/KOAECE23-4-09

Kim, H.-J. (2001). The effect of problem-based learning on the development of self-directedness of students (Master's thesis). Retrieved from http://www.riss.kr/link?id=T10348025

Kim, K. H. (2001). The effect of problem-based learning on children's critical thinking ability (Master's thesis). Retrieved from http://www.riss.kr/link?id=T8875517 
Kim, K. S. (2002). Effects of problem-based learning on the learner's problem solving ability and sociality (Master's thesis). Retrieved from http://www.riss.kr/link?id=T8175468

Kim, K.-S. (2009). The effects of applying the arithmetic educational activity based on young children's daily-life experiences (Doctoral dissertation). Retrieved from http://www.riss.kr/ link?id=T11584920

Kim, M.-F., \& Kim, S.-R. (2014). The effect of reading activity using mathematic-related fairy tales based on mathematizing on young children's mathematical ability and mathematical attitude. Journal of Childrens Literature and Education, 15(1), 97-119.

Ko, B. (2015). Practical application of the materials of teaching using mathematics history (For the first grade in middle school student)(Master's thesis). Retrieved from http://www.riss.kr/ link?id=T13712226

Kwon, Y. (2003). Yuasuhakgyoyuk [유아수학교육]. Seoul: Yangseowon.

Lee, E.-H., \& Kim, S. (2015). The effects of mathemmatical program based on forest experience activities on young children's mathematical attitude. Journal of Early Childhood Education \& Educare Welfare, 19(2), 5-29.

Lee, E.-Y., \& Jeon, Y.-Y. (2012). The effects of activities with picture books focused on using the mathematical vocabulary on young children's vocabulary and mathematical problem solving ability. The Journal of Korea Open Association for Early Childhood Education, 17(2), 47-71.

Lee, H. S. (2002). A study on PBL-based good citizenship classes and class planning and evaluation cases (Master's thesis). Retrieved from http://www.riss.kr/link?id=T8133198

Lee, J. (2015). A study on math motivation, mathematically affective characteristics and mathematical achievements between gifted and non-gifted students based on Keller's ARCS theory (Master's thesis). Retrieved from http://www.riss.kr/ link?id=T13819593

Lee, J. Y. (1997). Social problem solving behavior of children (Master's thesis). Retrieved from http://www.riss.kr/link?id=T937762

Mun, B.-H., \& Cho, E.-J. (2017). The effect of mathematical activities through inquiry-based on young children's mathematical disposition and mathematical problem solving ability. The Journal of Korea Open Association for Early Childhood Education, 22(3), 279-299. doi:10.20437/ KOAECE22-3-12
Na, G. O., \& Kim, K. H. (2003). A study of mathematical process in kindergarten. Soonchunhyang Journal of Institute Humanit, 12, 21-41.

Oh, S. H., \& Kim, Y. O. (1997). The effects of teacher inquiry methods on interpersonal cognitive problem solving ability. Korean Journal of Child Studies, 18(2), 299-310.

Park, J.-Y., \& Hwang, H.-I. (2006). The differences of mathematical abilities and attitudes according to children's mathematical learning potentiality. Journal of Early Childhood Education, 15(1), 27-47.

Schwab, K. (2016). The fourth industrial revolution (J. Song, Trans.). Seoul: New Present. (Original work published 2016)

Seo, Y. M. (2008). The effects of mathematical inquiry activity based on the forest experience on children's mathematical problem solving ability and attitude toward mathematics (Master's thesis). Retrieved from http://www.riss.kr/ link?id=T11228930

Shin, I. S., \& Lee, S. J. (2003). The effect of mathematical activities using mathematics-related fairy tales on children's mathematical problem-solving abilities. Journal of Future Early Childhood Education, 10(4), 89-112.

Song, M. J. (1989). Munjehaegyeolsago: Mueosi eotteoke baldalhaneunga? [문제해결사고: 무엇이 어떻게 발달하는 가?]. The Keimyung Journal of Behavioral Sciences, 2(1), 4560.

Yang, S. (2019). The development and effects of daily-based preschool math education program to improve mathematical problemsolving (Doctoral dissertation). Retrieved from http://www. riss.kr/link?id=T15058079

\section{ORCID}

Jihyun Kim https://orcid.org/0000-0001-7263-3008

Sunyoung Yang http://orcid.org/0000-0001-9329-7955

Received February 28, 2019

Revision received April 16, 2019

Accepted July 8, 2019 


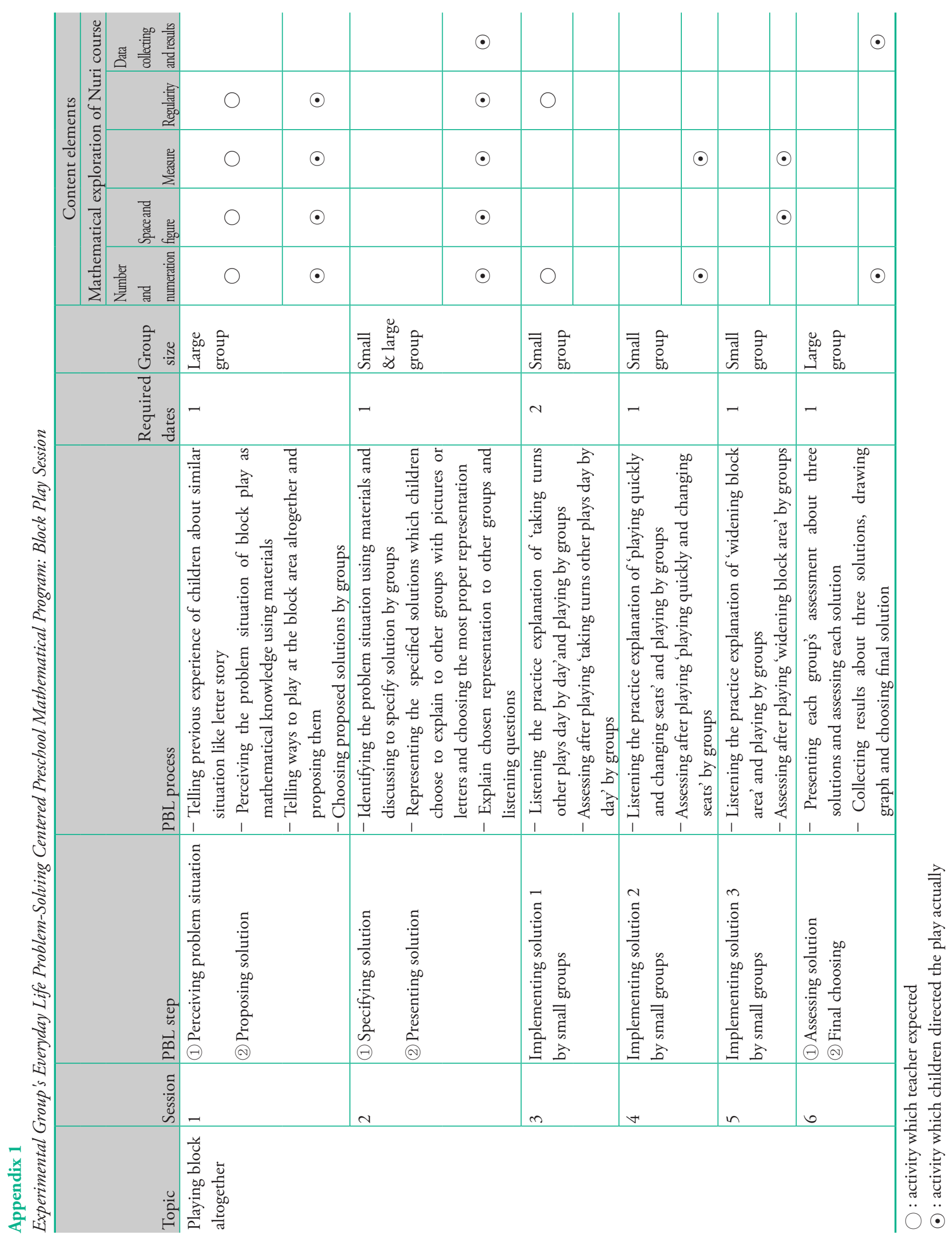

